\section{Changing Focus}

\section{Mark Andrea de Cataldo}

\section{Alla memoria di mamma e papà, con amore.}

I write down here a few thoughts about changing the direction of one's research, mostly by referring to my personal experience. It is not my intention to have the reader interpret my writing as a description of a move towards "better" math (whatever that means). Very plainly, I have tried to share selected memories of what happened when I met new math that I found to be interesting and beautiful. Math that I could not resist. It would be silly to try to pose that what follows contains any kind of universal truth. I hope the young reader glances at these recollections and draws some hopefully useful conclusions.

\section{In My Youth}

In my youth, I had lots of fun playing rugby as a left-wing for the University of Milano. In this role, change of pace and direction are very important, and they occur as if in a dizzying ride, the result of the split-second decisions you make running with the ball. The speed at which they occur notwithstanding, these changes are planned. On the other hand, I think that, more often than not, the changing of research direction does not occur because of a choice made at one point in time. Oftentimes, it is the result of a series of (mostly) fortunate events. This new evolution is not a sudden occurrence but the result of a mental disposition towards the beautiful math that comes to us by reading, thinking, working out problems, writing, and, most importantly, talking to people.

\section{Grad School: Midwest}

As a graduate student, I had been working on a problem I did not like. Ah! What a unique situation I found myself in. At that time, higher-dimensional algebraic geometry was in a boom (still is), and, darn it, I wanted to be part of it. So I set myself to work on it, drop my problem, change advisor, and do great new things. Bust! It came to nothing. The field itself was very exciting, but I was unprepared to enter it for what I now think was the wrong reason. I backtracked. However, I did not go back to the old line of work. With the help of my (very patient) advisor, I found myself a new problem, involving the special properties of codimension two submanifolds of complex hyperquadrics, solved it for the most part, and got a few papers out of it. And a degree.

Mark Andrea de Cataldo is a professor of mathematics at SUNY Stony Brook. His email address is mark. decataldo@stonybrook.edu.

DOI: https://dx.doi.org/10.1090/noti2079

\section{Postdoc Numero Uno: Midwest}

Postdoc! First job! Two years. Upon arrival, in the early fall of so many years ago, I submitted my first NSF grant research proposal. In writing it, I realized, to my horror, that I was not interested in the problems I came up with and was proposing. The subsequent decline letter from the foundation only confirmed my suspicion that many others were in total agreement with me. Meantime, I had stumbled upon some new beautiful math, estimates for solutions to $\bar{\partial}$ and applications to algebraic geometry. I started a learning seminar with faculty and graduate students. I asked myself a question, answered it, wrote two papers and my second NSF proposal, which was funded just in time for my second postdoc to begin.

\section{Postdoc Numero Due: Germany}

Postdoc! Second job! One year. Upon my arrival in Germany, a math physicist said, "Ah! You are an algebraic geometer. Why don't you explain to us, in a series of talks (not one, not two... a series of them, as many as you need), the action of the Heisenberg algebra on the cohomology of the Hilbert scheme of points on a surface?" I said, "Uh?" The truth is, I did not want to do it: I did not know that field; it would have been too much work; I wanted to focus on $\bar{\partial}$; I could not care less. I needed to get out of this predicament. But the physicist was...my office mate. I tried avoiding him. I failed. He was gently persistent. Hey, he was a fun guy with a great disposition - towards math, and towards life. I started reading up. Wow! Love at fifteenth sight. It took a lot of work to start realizing that I liked very much what I was not fully understanding. By the end of the year, my second postdoc was over; I was working a little bit on the $\bar{\partial}$ project, and more on Hilbert schemes.

\section{Postdoc Numero Tre: East Coast}

Postdoc! Third job! One year. Fancy US institution. Fellowship from the AMS (thank you). Stellar mentor. But (there is always a "but") I felt something was a bit off: I had been awarded the NSF grant, the fellowship, and the postdoc because of $\bar{\partial}$, but I could not stop binging on Hilbert schemes. Was I even on the right track? Upon arrival, a newly minted postdoc, a fellow algebraic geometer, explained in very, very lengthy detail his achievements and his goals. He asked me about my work, and ten seconds into my pitch, he dismissed me quickly: "That's not algebraic geometry." What should you do when something like this happens? I smiled. During that year, I ended up devoting a lot of my attention to finding a tenure-track job, giving over two dozen talks, and straddling the two research topics. I know now that nothing was off. Math, as a whole, must invest in its own future: encourage young people to try new things.

\section{Tenure-Track: Long Island}

Tenure-track! Move to Long Island. Benefits, tenure-clock, dean, sub-dean, uber-dean, mini-dean, provost, president, 
chair, departmental politics, grant proposals, teaching, setting up a webpage (1999! Still have the same one; looks like it's from 1993). More importantly, what to do mathwise? My good old friend $\bar{\partial}$ was no longer on my horizon. Hilbert schemes? Yes, but it was not the Hilbert schemes anymore, really. Somehow, the topology of complex algebraic varieties, with its difficulties, was occupying my thoughts. It had started dwelling in my mind without much fanfare as a result of thinking about Hilbert schemes. It was there, and it did not budge. What was going to happen? I was on tenure-track, needed to write papers, get grants, and this math was so new to me (and so weirdly exciting). What if it did not pan out? What about the grant renewal? Tenure (tick-tock)? In the end, there was really no choice. It was too interesting, difficult, and beautiful. The light was too blinding. I went towards it, and that was it. Luckily, as it turned out, it was not a truck.

\section{Today}

Undergrad years, compulsory military service, grad school, postdocs, tenure-track, promotions... It's all a vivid, awesome blur. There have been more changes in direction since then, but, at least mathwise, none more pronounced than the ones of my younger years. When I look back (when do I do that? There's no time!), it seems to me that the real changes of direction in my research were not recognized by me as such when they started happening: I was simply drawn to work on something that fascinated me, and to do that, I needed to learn and discover new math. And it was fun, pure and simple. At some point, suddenly, I found myself already moving in a new direction. It seems that there was no moment in time when I made a conscious decision to change. Quite simply, it just happened. And I am very, very happy it did.

\section{Mentoring Undergraduate Research: Advanced Planning Tools and Tips}

\section{Courtney R. Gibbons}

My first experience with mentoring undergraduate researchers was as the undergraduate mentee, and the critical importance of that summer features prominently in my mathematical coming-of-age story. That summer was a success because my mentor had a pretty clear idea of what we would do: the problem, the schedule, the follow-up. With this in mind, I'm sharing five homework exercises that I

Courtney R. Gibbons is an associate professor of mathematics at Hamilton College. Her email address is crgibbon@hami 1 ton. edu.

DOI: https://dx.doi.org/10.1090/noti 2078 assign to myself (now that I'm the mentor!) to make sure that my students and I have a fun and productive experience.

But first, a reminder: Whom you mentor matters. Students form their mathematician identity through their experiences with us, the mathematicians in their lives. Our outside recognition of them as "the kind of people who do math" is a component of this development, especially for students who don't see themselves represented in mathematics often or at all. For an entry into the literature on this topic, see the recent paper [RCJ19] and its thorough bibliography. The upshot? Inviting students from underrepresented groups in mathematics to work on our research projects is one way of committing to diversity and inclusion in our profession.

\section{Exercises}

I recommend completing these exercises several months in advance of your anticipated research project with undergraduates. For example, if you are thinking of working with students over a summer, consider working on them between the fall and spring semesters.

Exercise 1. Answer two questions: What do you hope to get from the collaboration? What do you hope your students get from it?

Your answers here (and below) don't need to be deep, philosophical reflections; keep it workable. For example, when I was a pretenure REU mentor, my goal for me was to produce a paper with my team. My goal for my team was to give them each ownership over specific parts of the project.

It's a good time to state that every piece of advice comes with exceptions! While I usually ask students to work on a project I designed, I've had gung-ho students pursue their own problems, and they've come up with surprising (to me) approaches and results. In those cases, I revised my goals for myself and made sure I felt like I had enough background to jump in and help.

Exercise 2. Write up a project proposal, including the problem(s) and a potential pathway to a solution.

The first time I did this, I didn't have a choice. I had agreed to be a visiting REU mentor, and I had to write this as part of the grant proposal. I think it's the most useful exercise on the list. From this, you will figure out what kind of background your future research students will need and what supplemental material they'll need to learn. You will start to see how to divide up the project into parts.

You can guide students along a path and stay a few steps ahead of them. You can even assign students some preliminary homework if they seem interested in working on research with you!

Exercise 3. Decide on the length of the collaboration and structure your time.

1. Break the project into phases: ramp-up (literature review, "classes" to cover background material, and time for students to build up stamina), active research, and 